\title{
Desconstrução da bipedia compulsória na Dança
}

\author{
Deconstruction of compulsory bipedal in dance
}

DOI: http://dx.doi.org/10.5965/19843178164202059

Carlos Eduardo Oliveira do Carmo (Edu O.)

Universidade Federal da Bahia - UFBA eduimpro@gmail.com | ORCID | LATTES

Fátima Campos Daltro de Castro

Universidade Federal da Bahia - UFBA fadaltro@gmail.com | ORCID | LATTES

\begin{abstract}
RESUMO
Uma simples presença, seja de que ordem for, pode desencadear uma série de acontecimentos ao corpo. E, se todo corpo é corpomídia, isto é, mídia de cada momento do seu estado, os discursos poéticos que daí emergem são entendidos como historicamente produzidos e correspondentes às experiências que constituem o corpo. Quando trazemos tais pensamentos para com eles investigar a construção da dança em múltiplos corpos fica evidente a propriedade do corpo como um processo vivo, cognitivo e auto-organizador. No entanto, quando se trata do corpo com deficiência que dança, o retrocesso se impõe e a soberania do pensamento bípede que exclui essas pessoas entendendo-os como incapazes e não produtivos, independente de todo avanço no campo da dança, é evidente. A dança nesse texto é como um recorte (microespaço) que revela, em si, todo comportamento social (macroespaço). Entendemos que este campo de construção do conhecimento que é a Dança colaborará na interseccionalidade com outras áreas, a partir de como estabelece e compreende as relações de corpo. Dança e corpo que dança como um recorte de nossa estrutura social, onde é possível perceber discursos do pensamento hegemônico que mantém padrões funcionais e corporais excludentes em relação às pessoas com deficiência. Palavras-chaves: Corpomídia; Dança; Bipedia Compulsória;
\end{abstract}

\section{ABSTRACT}

The presence of any kind can trigger a series events to the body. The body as corpomedia, that is, media of its state, of each moment of its state, the poetic discourses that emerge there are understood as historically produced and corresponds to the experiences that constitute the body. Considering this, the investigation of the construction of the dance in multiple bodies, the propriety of the body as a living, cognitive and self-organizing process becomes evident. However, when it comes to the disable body dances, the kickback about that body. The sovereignty of bipedal thinking that excludes these people as unfit and unproductive, regardless of any advance in the field of dance, is evident. The dance in this context, is a clipping (micro space) that reveals, in itself, all social behavior (macro space). We understand that this field of knowledge construction that is dance will collaborate in intersectionality whit other areas, based on how it establishes and understands body relations. Considering Dance and body that dances as a clipping o four social structure, it is 
possible to perceive discourses of hegemonic thinking that maintain exclusive functional and body patterns in relation to people with disabilities.

Keywords: Corpomedia; Dance; Compulsory Bipedal;

\section{O QUE PODE O CORPO QUE DANÇA? O QUE PODE O CORPO COM DEFICIÊNCIA QUE DANÇA? AINDA É PRECISO DIFERENCIAR OS CORPOS QUE DANÇAM?}

O entendimento de corpo, nos tempos recentes, modificou-se trazendo ângulos de visão diversificados. A partir de estudo dos processos evolutivos, pôde-se compreender o corpo como parte do ambiente e, como tal, sofrendo e produzindo interferências, modificando-se, ao mesmo tempo em que interfere e também modifica o ambiente. Nessas transformações de mão dupla, os alvos precisam ser sempre móveis para se manterem adaptados ao ambiente em que vivem. O corpo modifica-se o tempo todo, o que favorece e aumenta as suas chances de sobrevivência. Esse conceito de corpo junto às potencialidade que thes são inerentes e, portanto, também ao corpo de pessoas com deficiência, foi formulada na Teoria Corpomídia (GREINER; KATZ, 2005), abrindo novas frentes de discussões. Para ela, o modo como cada corpo se torna corpo interfere diretamente em suas escolhas e tomadas de decisão.

Esse pensamento nos coloca frente ao corpo como um sistema vivo sempre em processo, apto a construir o ambiente e a si mesmo, em um incessante fluxo de trocas entre ambos. Tudo que vira corpo depende da mediação da percepção daquilo que acontece no trânsito entre o dentro e o fora do corpo. Sendo o corpo singular, cada qual desenvolve os seus próprios critérios, mas tudo do corpo é mutante, pois ele está sempre em constante transformação. Um corpo sempre se diferencia dos demais e nessa diferenciação não precisa ser entendido como corpo produto, algo dado a priori.

Inevitavelmente, o corpo é um organismo em processo e imerso em formas de vida que o atravessam (KATZ, 2005). Como um sistema cognitivo, é complexo e está apto a se organizar de forma que possa trocar informações. Esse pensamento 
ajuda-nos a compreender que a vida inteligente não apresenta descontinuidade. Podemos afirmar que todo e/ou qualquer sistema que explora, tanto as informações por ele já contidas, quanto o fluxo de energia que o atravessa, trabalha de forma a aumentar as informações já existentes (CHURCHLAND, 2004).

Ocorre uma intensa criação de alianças estruturais, especialmente, entre a ordem interna (cognitiva) e as condições externas (LLINÁS, 2003). O pensamento evolutivo aplica-se a todos os tipos de corpos. Como explica Katz (2005), o conhecimento muda porque os acessos aos objetos e os próprios objetos também se alteram. A cada nova descrição, descreve-se um novo objeto.

Podemos clarificar essa experiência durante a realização de um movimento mais complexo com o corpo, quando ele é desafiado a realizar algum movimento, girar, por exemplo, experimentando outras bases de apoio tais como, as costas, os quadris ou um ombro - qualquer ação exige esforço físico para lançar o corpo no espaço. A princípio, o giro, sob uma base incomum, exige um esforço superior ao que o corpo não está habituado a realizar e, com o tempo e a repetição, as mudanças instalam-se no corpo melhorando sua resposta física e mais conforto durante a execução. Todo corpo aprende como realizar o movimento utilizando esforço mínimo, ou seja, usar apenas o esforço necessário à ação. Treinamentos específicos certamente desafiam o corpo para o que se pretende alcançar.

Parece-nos um tanto óbvio dizer que o corpo da pessoa com deficiência terá uma presença marcante nas discussões que seguem no texto. No entanto, o repetimos; repetimos porque é mais do que necessário revigorar suas ações em busca do seu lugar de direito e de fala, uma vez que os processos de desvalorização a que foram e são submetidos, além de corroerem sua autonomia, seguem presentes no mundo, disfarçados de modos bem peculiares, tais como, na recusa de um taxi, no olhar do outro, ao ser abordado sem pedir licença, não ter espaço de locomoção e de boa flexibilidade em escolas, universidades, espaços culturais...

Poder viver experiências comuns a qualquer pessoa é bom e salutar. Todos nós, seres sociais, precisamos do convívio com amigos, colegas e passantes, do ir e vir corriqueiro do dia a dia quando bem se quiser para se apreciar as informações, 
os amores e também as dores que cercam nosso mundo, nossa vida. Viver em comunidade e usufruir de todos os bens que a circulam é parte importante. No entanto, em nossos espaços discursivos a constatação de que há um modo comum que perpassa a dança e o corpo do dançarino com deficiência, cuja tendência é traduzir e difundir imagens desses corpos que chamam a atenção para o que se considera defeito do corpo, inviabilizando suas potencialidades. Tais imagens ou performances valorizam aspectos do corpo como subutilizados, comungando predisposição à vitimização, à marginalização. Visão distorcida que estimula e difunde a ideia de que a pessoa com deficiência é uma coitadinha, uma vítima e, por isto mesmo, intocável.

Os resultados encontrados na pesquisa de doutorado da pesquisadora e também autora deste trabalho, (CASTRO, 2007), contradisseram cabalmente essa visão, apresentado-se para se opor, em alguma medida, ao crescente pensamento hegemônico que utiliza o aproveitamento dos sinais do corpo como meios para alcançar espaços de representatividade. Assim pensada, a temática se propõe como uma tentativa de romper com o paradigma do estigma do corpo deficiente, vitimizado, inscrito a partir do olhar do outro, podendo, a depender das circunstâncias, transformar-se em uma experiência desestruturante.

No contexto da dança existem muitos discursos eficazes na arte de persuadir. $E$ os discursos da inclusão que vêm embutidos nas políticas públicas e nos encontros realizados por instituições dedicam-se a construir modelos destinados a obter ou reforçar a adesão àquele tipo de entendimento. De maneira convincente, as performances desses corpos e a veiculação de suas imagens na mídia fomentam a crença de que se está, realmente, efetivando-se o exercício da inclusão. Mas o que, em realidade, ocorre, é justamente a efetivação perversa da exclusão. Ela é sutil, pois se faz pelo mecanismo nomeado de 'exclusão pela inclusão' e permite a aparição camuflada, mimetizada do corpo (AGAMBEN, 2002).

A exceção é uma espécie de exclusão. É um caso singular, que é excluído da norma geral. Mas o que caracteriza propriamente a exceção é que aquilo que é excluído não está, por causa disto absolutamente fora da relação com a norma; ao contrário, esta se 
mantém em relação com aquela na forma de suspensão(...). Chamemos relação de exceção a esta forma extrema da relação que inclui alguma coisa unicamente através da sua exclusão. (AGAMBEN, 2002, p. 25, 26)

Um estado de exceção permanente, um arranjo que, semelhante ao Estado de Sítio, captura os direitos da livre expressão desses artistas. O incluir excluindo revela-se na exigência da contrapartida. Para obter o passaporte da acessibilidade, para ter representatividade midiática é necessário que se concorde com a situação do "corpo coitadinho fazendo arte" e que negue o corpo estrutural, biológico e culturalmente apto para construir conhecimentos. Essa forma de inclusão exige singularidade excluída. A norma aplicada é a invisibilidade poética, o estar presente, mas, ausente de si. Aos corpos/dançarinos com deficiência de um modo geral e específico é vedado o direito da livre expressão, o direito de vivenciar experiências vitais, porque corpo que foge e fere as normas vigentes. É bom lembrar que esse comportamento se aplica não apenas ao universo da dança, mas em todos os âmbitos da sociedade. A norma aplicada serve para incluir o expulso (AGAMBEN, 2002).

Mesmo com todos os avanços evidentes nos processos de construção de conhecimentos e as flexibilidades que ocorreram nas fronteiras que cercam a dança contemporânea, a corporeidade da pessoa em condição de deficiência (ZOBOLI; BARRETO, 2006) que dança vive sob a égide do pensamento bípede, um pensamento comum e simplista, que nega o corpo em sua complexidade de interação, organização e transformação. A "construção de conhecimento se dará sempre na relação com o outro" (KATZ, 2005, p.53). Lançar mão da expressão Bipedia Compulsória, que é um campo conceitual ainda em desenvolvimento, criado por Carmo (2019) em sua de pesquisa no Doutorado Multinstitucional e Multidisciplinar em

Difusão do Conhecimento (UFBA-UNEB-IFBA-UEFS-LNCC-SENAI-CIMATEC), certamente nos ajudará a elucidar os equívocos do mundo contemporâneo, especificamente o pensamento bípede que cerca essas pessoas. 
O conceito de Bipedia Compulsória defendido por Carmo (2019) é compreendido não como forma de locomoção sobre dois membros, mas uma estrutura social, política, econômica e cultural que determina padrões excludentes pautados na normatividade do corpo, que subjugam $e$ inferiorizam as potencialidades da pessoa com deficiência, tomadas por incapazes e inaptas (CARMO, 2019, p. 78). É uma lógica de organização social que parte da perspectiva de quem não possui deficiência e exclui, invisibilizando qualquer outra experiência de corpo que seja considerado doente, inapto, ineficaz, deficiente. Importante compreender que o termo bipedia nessa abordagem foge da literalidade do seu significado, pautado na estrutura física, biológica e na marcha dos humanos, mas aproxima-se do modelo histórico-cultural da própria deficiência.

Estudos recentes sobre a deficiência, mais especificamente a Teoria Crip, apresentada por Robert McRuer (2006), compreende o corpo com deficiência como uma construção histórico-cultural. Ao analisarmos o desenrolar da história percebemos como o conceito da deficiência vem sendo modelado e manipulado por diversos interesses políticos e econômicos. A maneira como a narrativa da deficiência tem sido construída pela medicina, o movimento eugênico que estabeleceu padrões de normalidade e controle da população provocando a morte de pessoas com deficiência, a relação entre deficiência e degenerescência, o descarte das pessoas consideradas inaptas, incapazes e improdutivas para o trabalho, entre tantos outros momentos da humanidade (LOBO, 2008).

Retomando ao entendimento da bipedia, para Edu O. (como o autor deste texto é mais conhecido), em sua pesquisa, a normatividade do corpo assim como a deficiência, é uma construção histórico-cultural. Isto porque qualquer corpo, em seu processo de construção e transformação, elabora a si próprio em codependência à sua história de vida.

Sabemos que a bipedia se ocupa de um processo de desvalorização do outro, no entanto, o corpo, entendido como mídia de si mesmo - corpomídia - está sempre em movimento e em transformação, em continuidade. Para Vieira (2006) o corpo é um sistema aberto móvel, e por ser assim, modifica-se a cada instante de 
vida. Nesse jeito de ser "o próprio corpo resulta de contínuas negociações de informações com o seu ambiente e carrega seu modo de existir para outras instâncias do seu funcionamento" (KATZ, 2005, p. 8).

"Tudo aquilo que o corpo está apto para receber ele não recusa, ele entra em processo de negociação com cada uma das possibilidades que se atualiza de acordo com a lei biológica que as governam" (KATZ, 2005, p. 140).

Por exemplo, as possibilidades das variantes dos esforços do corpo para se manter em equilíbrio, corpo atentivo para vencer a ação da gravidade em pé ou sentado, opor-se às forças externas de distintas ordens, situar-se no tempo espaço que o envolve para elaborar a melhor escolha, ajustar-se às contínuas informações que o atravessam, se interessantes ou não, as que implicam em infindáveis tentativas de se desvencilhar das velhas descrições que vêem o corpo como um instrumento do determinismo social.

Corpomídia, corpo, qualquer corpo é transitoriedade e tendencialidade. Se o corpo em sua multiplicidade é munido de um sistema que o provoca a construir conhecimentos e trocar experiências no mundo em que vive, por que, diante de todos os avanços e questões levantadas, ainda é persistente e sistemática a desvalorização do corpo da pessoa com deficiência que dança? Por que o pensamento bípede, até os dias atuais, encontra suporte que impõe a exclusão dessas pessoas? Por que suas corporeidades, diferenças e identidades ainda são compreendidas como algo dado a priori, mesmo sabendo que são produzidas no contexto de relações culturais, políticas, psicológicas, sociais e que todos nós estamos envolvidos? Sim, somos todos diferentes em nossas singularidades, particularidades e identidades. Sentimos, pensamos e agimos em acordo com o ambiente que nos cerca. Por exemplo, a frase - Vocês, bípedes, me cansam!, que é veiculada em uma página (via web ${ }^{1}$ ) de Edu, soa como uma provocação e traça um pensamento político de inserção com fins de criar campos argumentativos, e não apenas recomenda o respeito e tolerância para com a diferença/identidade como é comumente alavancado.

\footnotetext{
${ }^{1}$ Edu Oliveira realizou, em 2019, uma série de videos intitulados "Vocês, bípedes, me cansam!",
} disponíveis no IGTV de sua conta do Instagram - @eduimpro 
Aqui abordamos reflexões que propõem deslocamentos teóricos e exigem a urgência de pensar o mundo de outro modo e entender as forças diferentes que sustentam e dão voz às pessoas com deficiência. O modo como se expressam, o modo como dançam suas danças revelam os pensamentos construídos por eles. Por que não produzir outras imagens dessas pessoas? Imagens das suas qualidades?

Silva (2019) entende que essa seria uma posição social e pedagogicamente aceita, questionando "quais as implicações políticas dos conceitos de diferença, identidade, diversidade, alteridade?" (SILVA, 2019, p.74). A afirmação "Vocês, bípedes, me cansam!", exclamação ambígua, tendenciosa, em tempo, um chamamento para a aproximação fecunda que busca clarificar os incômodos tanto das pessoas com deficiência e quanto das pessoas bípedes. Suas diferenças e identidades codependentes, tais como todos os corpos os são, codependentes dos ambientes/contextos onde vivem. Se produzimos e construímos ativamente as nossas diferenças e identidades em codependência com o ambiente, certamente, elas irão traduzir os desejos dos diferentes grupos sociais assimetricamente situados, para garantir acesso privilegiado aos bens sociais, bem como a possibilidade de ações inovadoras. O novo assusta.

De qualquer modo, em todo e qualquer processo de diferenciação (afirmação da identidade e marcação da diferença) o poder tem presença marcante e é construído nas relações que as próprias diferenças e identidades constroem, o que implica sempre as operações de inclusão e exclusão - incluir para excluir. Por exemplo, nós e eles, incluir e excluir, bons e maus, desenvolvidos e primitivos, entre outros. Questionar a identidade e a diferença como relações de poder significa problematizar os binarismos em torno dos quais elas se organizam. Diferença e identidade, como todo e qualquer sistema de significados é uma forma de atribuição de sentidos, são processos de produção social.

A questão é complexa, e não se pretende aqui explorá-la em todas as dimensões, mas fazer um recorte nos modos de representatividade desses corpos na mídia e nos espaços de construção de conhecimento, para buscar assim meios 
de negociação que viabilizem a sua presença nos espaços, desestruturando o pensamento hegemônico e trivial, porque comum, do corpo vítima e incapaz, coitadinho que é explorado na arte, em especial na dança, ao se negarem as potencialidades que emergem desse grupo de pessoas. Vocês, bípedes, me cansam! Podemos dizer que onde existe diferenciação - ou seja, identidade e diferença - aí está presente o poder (SILVA, 2019).

\section{CORPOS DIFERENTES E DE IDENTIDADES MARCANTES... TODOS NÓS!}

Pensando junto, logo, compartilhando pensamentos, em um dos seus textos sobre bipedia compulsória (CARMO, 2019), Edu O. parte instigante de sua pesquisa de doutorado, leva-nos a lugares desafiadores e de incômodos. Os lugares incômodos das tendências que seguem padrões pré-determinados, modelos impostos e alheios à singularidade desses corpos. E, para tal, aqui propomos uma reflexão sobre a implicação da proliferação de imagens na construção de sentidos, tanto do corpo desses dançarinos quanto no imaginário da sociedade que trazem em seu bojo as ideias do pensamento bípede, discursos hegemônicos e equivocados que difundem a ideia do corpo deficiente que dança como fonte de improdutividade e de invalidez permanente. Tais pensamentos irrigam os métodos que trabalham a construção da dança nesses sujeitos que, materializados como dança, se impõem como categorias paralisantes, transformando a sociedade e deslocando-os para territórios estritamente excludentes (BAUMAN, 1999).

A partir das discussões que o texto propõe compreendemos que avançamos muito pouco, mesmo levando em consideração a flexibilização das fronteiras no campo da Dança Contemporânea e nos estudos acerca da complexidade do corpo. Ainda é evidente a exclusão de corpos/pessoas que não atendem aos padrões normativos, do corpo virtuoso e ideal pra a dança. O corpo sem defeito, limitação, problema, doença, dificuldade... todas as palavras agregadas à deficiência que revelam a ignorância e a própria limitação dos bípedes ao não conseguirem ampliar 
sua compreensão sobre a complexidade e o universo de possibilidades apresentadas pela deficiência.

A própria associação da virtuose como qualidade da bipedia, em muitos casos, servindo de critério para se estabelecer quem pode ou não dançar, cai por terra ao observarmos mais de perto alguns atletas e artistas com deficiência como, por exemplo, os praticantes de Esportes Radicais, o dançarino estadunidense Bill Shannon que desenvolve pesquisa de dança em seu skate ou ainda alguns trabalhos da Candoco Dance Company, de Londres. Por outro lado, quantos dançarinos bípedes não se utilizam da virtuosidade, e nem por isso são questionados em suas qualidades e potencialidades corporais?

Não podemos compreender a deficiência, assim como nenhum grupo ou nenhum corpo, de forma generalizada. Inclusive porque existe uma diversidade enorme de deficiências e é necessário compreende-las em suas especificidades e na interseccionalidade com questões de classe, economia, gênero, periferia/centro, oportunidades de educação, mobilidade, enfim, uma série de fatores que determinam o estar da pessoa no mundo.

No campo da pesquisa, a discussão emergente acerca do corpo e do corpo que dança cria campos relacionais largamente potentes de conhecimentos. No entanto são visíveis e intoleráveis os descompassos da história de vida de pessoas/corpos que não atendem às demandas dos padrões e o cerceamento do mercado financeiro e de produtividade que giram nesse entorno. A dança em sua materialidade é múltipla e o corpo em sua corporeidade também o é, ambos em suas complexidades transformam-se mutuamente para expor a expertise do viver junto. "Celebram por distintas vias em conexão o respeito e a riqueza da multiplicidade. Sempre restrito, o corpo que dança é, simultaneamente, o lugar onde a dança acontece e o agente produtor dessa dança" (KATZ, 2005, p. 254).

Se o corpo e sua dança interagem entre si e se a coleção de informações a que estão submetidos são sempre móveis, há que se pensar em desenvolver ações contra a homogeneização e o fechamento de ideias. As velhas ideias criam acordos de ordem e tem a finalidade de desqualificar social, política, financeira, arquitetônica, 
psicológica, filosófica e culturalmente (insistindo: tudo junto) o corpo que não atende ao padrão desejado, seja dentro ou fora de casa. Os múltiplos corpos e suas danças constroem-se em codependência com a história de suas vidas, insistimos.

Com o objetivo de revelar os equívocos e quem sabe abrir uma brecha para que ventos inovadores ocupem o espaço com vontade, freando aqueles que buscam desqualificar o sujeito pensante, valem as reflexões: quais os modos de organizações do corpo que se constituem a partir das relações em distintos espaços? O que o espaço social da casa ou o espaço do ambiente urbano, ou qualquer outro ambiente oferece como desafio para o corpo? Quais os aspectos relevantes sobre o modo como se constroem as redes de interrelações entre dançarinos com deficiência e os meios de comunicação que, claramente expõem uma regulação subordinada e destinada a favorecer atores hegemônicos e em função de seus objetos particulares?

Todas as questões aqui levantadas aproximam-nos do pensamento decolonial. Um pensamento que levanta discussões (MIGNOLO, 2008) a partir da perspectiva da maioria das pessoas do planeta cujas vidas foram declaradas dispensáveis, cuja dignidade foi humilhada, cujos corpos foram usados como força de trabalho, tais como os africanos escravizados e os indígenas na formação da economia capitalista. Neste texto, ao criarmos campos de intersecção com o pensamento decolonial, temos uma importante oportunidade de suporte às discussões ora alavancadas, em tempo que impulsiona outros espaços de oportunidades ao imaginar um mundo no qual muitos mundos podem coexistir (MIGNOLO, 2008).

A dança, o corpo que dança, a pessoa com deficiência que dança, o gordo que dança, o afrodescendente que dança balé, entre outros modos de expressão via movimento... a dança é processo de construção de conhecimento via corpo. Muitos professores, curadores, gestores, artistas da dança e até mesmo estudiosos repetem tal afirmação em seus discursos, no entanto, negligenciam o corpo com deficiência em suas práticas e espaços de atuação. 
O que justifica professores e artistas da dança que ainda se negam a pesquisar novas metodologias e até mesmo recusarem-se a ter alunos ou pessoas com deficiência nas suas aulas e trabalhos artísticos? Por que os curadores ainda perpetuam um olhar capacitista, aquele da discriminação e do entendimento da incapacidade em relação à produção de artistas com deficiência?

$\mathrm{Na}$ programação dos festivais, eventos e práticas, na maioria das vezes, a Dança ainda é pensada para o corpo bípede, embora o discurso de corpo dos estudos da área aponte para o corpo em constante relação com o ambiente, o corpo apto cognitivamente para se adaptar e sobreviver, ou seja, para qualquer corpo e não para um corpo específico - o bípede. Porém, a bipedia que ocupa os espaços de saber e, consequentemente, de poder, delimita os espaços de exclusão e não abre mão dos seus privilégios.

Edu Oliveira compreende que "há um corpo que determina esse pensamento e toda estrutura social. Parece possível afirmar que esse é o corpo bípede, branco, heterossexual e cisgênero (cis) que até hoje ocupa os principais espaços de poder e saber" (CARMO, 2019, p. 91).

Sabemos que muitos eventos (seminários, bienais, festivais, congressos, etc.) têm promovido, regularmente, em espaços específicos dentro de sua programação, atividades temáticas que versam sobre corpos com deficiência, negros, transexuais, indígenas e outros considerados categorias identitárias e assim transformados em assunto. No entanto, seus realizadores não elaboram que o corpo bípede, cisgênero, branco e hétero é o assunto constante e permanente ao longo do tempo. Ao se categorizar um corpo como o Outro é porque se considera um modelo, o corpo a priori detentor do saber.

Edu O. lança uma série de questões e problematiza a presença exclusiva desse corpo hegemônico em espaços de decisão e poder. Este autor pondera que:

Se há uma convocatória para festivais ou editais, com um determinado número de trabalhos a serem selecionados, qual o corpo que determina o critério de seleção? Qual o corpo que pauta a curadoria? Quantas pessoas desses grupos citados anteriormente podem ser aprovadas? 
As pessoas com deficiência, negras, trans e gays são pensadas como rótulos, marcas, discursos particulares, fechadas em nichos, capazes de falar apenas sobre um tema, limitadas a um único discurso, porque, caso o evento abarque mais pessoas "fora da norma", pode tornar- se um evento "temático", e por isso são categorizados e escolhidos "os melhores" entre cada uma dessas categorias, criando disputas entre os próprios pares. Uma briga entre nós mesmos pela mesma fatia da pizza, pelas migalhas do pão.

Porém, defendo que o corpo bípede, branco, hétero e cis, que jamais é categorizado, nem transformado em "assunto", nem rotulado, deve também ser compreendido como um tema, como categoria que carrega discurso, principalmente porque é ele que pauta o principal discurso do pensamento hegemônico (CARMO, 2019, p. 81)

É importante chamar a atenção para o fato de que os discursos poéticos que emergem do corpo do dançarino com deficiência são historicamente produzidos e correspondem às suas experiências, ou seja, ao modo como a dança e o corpo constroem-se mutuamente ao longo da vida e diante de todas as interferências que os cerceiam. A dança, o corpo como um lugar por onde circulam sentidos sócio-históricos de produção, envolvida com sua própria materialidade, aquela que se produz no corpo, incrustada no corpo (KATZ, 2005).

O corpo que dança traz as características que são propriedades deste corpo, ele inscreve em si mesmo todos os embates das práticas a que é submetido e que permitem a sua identificação como um corpo dançarino. Uma reflexão desse porte propõe deslocamentos teóricos necessários para as pesquisas com a dança que é elaborada com essas pessoas. O corpo, como um discurso poético em funcionamento e construído a partir dele próprio; os processos sensoriais que acontecem entre ele (o corpo), o ambiente, a cultura, o cheiro, a voz, o modo de agir, de se vestir, de gesticular, de poetizar e, tudo simultaneamente, tudo em ação, misturado, imbricado, implicados estão.

A dança desses corpos, dessas pessoas, o dito corpo desqualificado da pessoa com deficiência cria e elabora as condições de predição a partir de seus sentidos perceptivos para resolver com propriedade as diversas situações que emergem no seu dia a dia ou em dado momento de uma ação de dança. A condição de predição do corpo é uma resposta aos processos evolutivos que o constituíram, e 
tal função é vital para movê-lo adequadamente, "é sem dúvida a função cerebral fundamental mais comum" (LLINÁS, 2003, p.24). Isso vale para qualquer corpo. Desse modo, pensar o corpo sob a perspectiva evolutiva é compreender que seu desenvolvimento se dá a partir das relações que engendra com o seu fazer no mundo, e como tal, se modifica ao tempo em que interfere e modifica o ambiente. Por isso mesmo, os seus alvos são sempre móveis o que favorece sua adaptação aos ambientes em que vivem. Nesse lugar, o comportamento atentivo é solicitado e exige que o corpo estabeleça regras táticas relacionadas com as propriedades do entorno no qual se move.

Corpo e a dança desse corpo são codependentes e imbricados, potencializando-se mutuamente, respondendo com eficácia ao que se está requisitando no momento. Para Llinás (2003, p.23), "é absolutamente indispensável que os animais antecipem o resultado de seus movimentos com base nos sentidos".

Mais uma vez, pensando o corpo, corpo que dança e corpo da pessoa com deficiência que dança, se todas as suas ações no ambiente podem desencadear ajustes e se a condição preditiva é vital para a sobrevivência, como é possível potencializar tal comportamento no controle do movimento corporal para que as elaborações de escolhas sejam eficazes no momento de encenação? E no dia a dia, para driblar as crueldades reveladas em ações deliberadas, tais como: esse corpo pode, aquele não, essa cor pode, aquela não, essa voz pode, aquela não? Quais as estratégias possíveis nesse intento? Como habilitar o corpo para antecipar com maior propriedade as condições necessárias à criação no ato de encenação e fora dele? Como é possível para o dançarino/coreógrafo, em certo momento da dança, antecipar para o seu parceiro ou mesmo disponibilizar no ambiente compositivo sua intenção de que logo precisará de apoio para se projetar no espaço? E, para que tal intenção se revele: qual esforço que demanda a ação para deslocar o corpo do chão em uma carrega? Quem, no momento da cena pode antecipar e dar continuidade ao que é proposto em acordos silenciosos? Ou, o que é possível propor na cena que gere poéticas em fluxo por todo o percurso da criação experimentando a escuta? Como são possíveis tais experiências às pessoas com deficiência interessadas em 
Dança, se estas não têm oportunidades de experienciá-las, se os profissionais e as escolas de dança pautadas na lógica bípede fecham as portas?

Todas essas questões, muitas delas já pesquisadas, demandam exercícios, experiências, dedicação, formação de hábitos em um processo racional e de autocontrole de modo a aperfeiçoar e atualizar cada possibilidade do dia a dia. Temos assim uma dimensão da complexidade em torno do corpo e de suas danças. Ao corpo com deficiência são também exigidas demandas para que possam se relacionar com os mundos possíveis. Para que resolvam da melhor maneira possível os desafios que emergem de situações inesperadas, na cena improvisada ou na vida, para elaborar escolhas com eficácia e que funcionem como disparadores para as dramaturgias de dança ou para encarar a vida com autonomia. Certamente o corpo está implicado em uma ação atentiva complexa tal como a demanda da atenção que envolve ter consciência do lugar onde se encontra e das relações possíveis de distância que pode estabelecer com outros dançarinos, a dosagem da projeção do próprio corpo no espaço para evitar os impactos desnecessários, em tempo que realiza seus próprios movimentos, criar e estabelecer as condições para a construção de significados que dêem sentido àquilo que se quer representar.

Inevitavelmente, o corpo, é um organismo em processo e imerso em formas de vida que o atravessam. Evolutivamente, as metas de cada espécie, incluindo o ser humano, passam por mudanças tanto culturais quanto genéticas. A ideia que sustenta essa argumentação sugere que o corpo, como sujeito biológico é cognitivamente apto, capaz de desenvolver habilidades específicas necessárias à prática da encenação da dança, e que esse processo em continuidade é fundamental para fomentar as condições necessárias para o aprendizado via corpo. A prática de processos colaborativos exige do coreógrafo/intérprete (no momento da encenação) que estabeleça com prontidão suas ações para resolver os problemas que emergem no percurso da criação. Como dito anteriormente, estando em movimento, os desafios surgem de diversas entradas do espaço cênico, as respostas e os ajustes entre os participantes precisam entrar em sintonia para tomar decisão com proveito e autonomia no momento presente. São soluções imediatas a 
partir das próprias experiências no campo colaborativo que precisam ser resolvidas rapidamente, o que predispõe ao corpo agir com rapidez e atenção redobrada. Tais procedimentos exigem treinamentos diferenciados e com tarefas que levam em consideração o corpo, qualquer corpo, na relação com o ambiente.

A improvisação em dança utilizada como preparação técnica do corpo exige treinamento específico para habilitar o dançarino/intérprete a desenvolver suas capacidades preditivas. Aquelas que respondem com prontidão às provocações no percurso de uma encenação, ou seja, a habilidade na capacidade de reação e interpretação que permitem a cada sujeito escutar a si mesmo, a seus companheiros e ao entorno para viabilizar a escolha coerente. A antecipação no momento da encenação, que significa um estado de corpo que o prepara para o que está por vir, é fator primordial e necessário para a resolução dos problemas do percurso de uma dança em construção colaborativa. Na cena improvisada, quando se inicia uma ação, certamente, esta surge de pontos distintos do espaço cênico que são fontes de inspiração e todos eles podem agir como disparadores de sensibilidades convergentes e ou divergentes. Em ação, a intenção de um movimento pode ou não ser captado por todos os envolvidos, no entanto, dá-se o início de um contexto. Todo esse processo é um tipo de construção de conhecimentos via neural, via corpo, via dança. O treinamento em continuidade e a exploração de mecanismos específicos para estimular estados de corpo perceptivos potencializará gradativamente o fazer da dança em colaboração. Consequentemente, precisamos do outro para construir a minha dança, a sua dança, a nossa dança.

A continuidade com as experiências desafiadoras promove a expansão e o que antes era indecifrável, aos poucos e gradativamente, vem à tona para esclarecer a dúvida, ou se impor como uma questão importante a ser refletida e investigada. Repetindo, a partir de toda informação com a qual o corpo entra em contato, ele encontra um modo para dialogar - o corpo com deficiência também. Viver a experiência no corpo o faz mover-se, preparar-se para algo, dando início a processos que o modifiquem. Ao se modificar no contato com uma informação (de qualquer ordem) de modo a compreender suas ações no mundo, e como os 
acontecimentos do mundo interferem em seu modo de pensar agir corpo, essa troca, por ser ativa, demonstra que o potencial de estabilidade não equivale à estagnação, mas à rítmica evolutiva (DEWEY, 2012). Os fluxos contínuos e o vai-e-vem das informações, em mão-dupla, impulsionam as ações e as trocas que fazem avançar e empurram para adiante as estabilidades móveis (KATZ, 2005).

Existe na natureza, mesmo abaixo do nível de vida, algo além do mero fluxo e mudança. A forma é atingida toda vez que se alcança um equilíbrio estável, embora móvel. As mudanças se entrelaçam e se sustentam. Sempre que essa coerência existe há persistência. [...] Por ser ativa, a própria ordem se desenvolve (DEWEY, 2012, p. 84).

Logo, em seu propósito, a vida se dá em um meio ambiente, não apenas nele, mas por causa dele, pela interação com ele, em um processo de troca de informações constante e em fluxos contínuos (KATZ, 2005; DEWEY, 2012). Para Richard Sennett (2012), a colaboração é uma habilidade que se desenvolve a princípio no ambiente familiar, nas práticas comuns da cotidianidade social (escolas, universidades) para resolver os problemas de convívio, tal como o de conseguir mediante colaboração o que não se pode alcançar sozinho.

A dança organiza-se em trajetos que se desviam e se bifurcam, o corpo também, o corpo da pessoa com deficiência também. Até quando precisaremos repetir? Ah! Vocês, bípedes, me cansam!

Criamos em condições de codependência, o que significa compreender o corpo e o mundo, relacionando-se beneficiando-se mutuamente, valorizando processos desenvolvidos colaborativamente, em detrimento de processos isolados ou individualizados. No corpo, as experiências sofridas no percurso da criação nunca serão meros retornos ao conhecimento anterior, mas conhecimento que, no contínuo trânsito de informações, viabiliza modos de organização enriquecidos pelas situações de disparidades que atravessou com sucesso nos seus processos de descobertas. 


\section{EXPERIMENTOS E EXPERIÊNCIAS QUE IMPULSIONAM A CRIAÇÃO VIA CORPO. EXPERIMENTOS E EXPERIÊNCIA VIA CORPO COM DEFICIÊNCIA? CORPO COM DEFICIÊNCIA QUE CRIA JUNTO A VOCÊ, A MIM E AOS OUTROS.}

Experimentamos o mundo através de diversas informações que invadem o corpo mediadas por nossas sensações e, imediatamente, construímos perceptualmente uma ideia aproximada do que vemos. Aproximada, pois a realidade em si mesma nunca nos é dada. Isso, porque representamos o mundo através das confabulações (conexões) que o cérebro realiza para construir uma imagem a partir de sensações recebidas, e que se organizam com bases nas experiências que temos do mundo vivido (DAMÁSIO, 1999; NOË, 2004).

Para Noë (2004), a percepção não é alguma coisa em nós, ou para nós, é alguma coisa que nós fazemos a partir das relações que construímos com o entorno para entender as situações. Podemos dizer que são os acordos que elaboramos com os mundos possíveis para enfrentarmos as dissonâncias e/ou ressonâncias referenciadas ao conhecimento que possuímos. Aquilo que podemos imaginar e realizar a cada momento dadas as sensações (histórias) vividas (visuais, sonoras, táteis, espaciais, psicológicas, políticas, culturais e/ou sociais). São ações ativadas corporalmente que proporcionam os meios para conhecermos e lidarmos com os desafios postos. Para esse autor, assim como para Damásio (1999), a percepção e a consciência perceptual são atividades de conhecer, assim como observar também é um tipo de habilidade corporal presente no nosso viver de cada dia.

$\mathrm{Na}$ dança, o processo de conhecer via corpo com/sem deficiência utiliza-se dos mesmos mecanismos, e nessa condição, as ações precisam organizar-se de um modo tal que as informações e seus arranjos constituam-se como significados simbólicos. Para tanto, é preciso explorar, experimentar, desafiar o corpo a sair do lugar habitual para enveredar em um ambiente onde os desafios e as incertezas possam surpreender. O outro, seja de que ordem for (objetos diversos, músicas, textos, meu vizinho, um amigo, o trabalho, o vento, o movimento, uma imagem, um filme, um comentário discreto), intervirá de alguma forma no que está em curso, 
colorindo em diversas nuances as tensões e intencionalidades do movimento (LOUPPE, 2012). O outro é o nosso desafio. Esse modo de organização é revelado quando o corpo compreende como a forma de suas sensações é fixada em função do movimento no espaço.

O que percebemos é aquilo que é determinado pelo que nós fazemos, ou o que nós sabemos fazer, logo, criar possibilidades de relação com o ambiente tem importância fundamental para conhecer algo (NOË, 2004, p.15).

Esse mesmo autor considera que o nosso sistema sensoriomotor e o conhecimento trabalham juntos para reproduzir a percepção do espaço, bem como objetos com os quais o corpo entra em contato, e dessa forma o movimento, o mover-se, é fundamental. Por exemplo, para as pessoas cegas, o corpo encontra contato no caminhar, no apalpar dos objetos, seus odores.

A dança é um tipo de experiência (capacidade perceptiva) que lida com habilidades práticas corporais para comunicar algo. O conhecimento sensoriomotor desenvolvido no contato com os distintos modos que essa prática apresenta, constitui-se um campo rico a favor do conhecimento. Nos processos criativos que podem surgir no contato com objetos e corpos diversos ele é acionado. "Para que a sensação perceptual se constitua como experiência, ter genuína representação de conteúdo, o observador precisa possuir e fazer uso de seu conhecimento sensoriomotor" (NOË, 2004, p.16). Ao contato com a multiplicidade criamos a nossa realidade aproximada da realidade que nos rodeia, e que se complexifica quando se leva em consideração os sujeitos que aí estão implicados, com seus modos de ver, ser e sentir o mundo para com ele dialogar.

Compor danças em ambientes onde há diversidade de pensamentos interessa-nos porque é possível criar as condições para o exercício da democracia, em tempo que nos habilita a lidarmos com os desafios que surgem de diversas frentes no jogo compositivo. Nesse sentido, a improvisação é um aliado potente, isso porque, para poder comunicar algo no momento do seu acontecimento, os dançarinos precisam viabilizar diálogos corporais que favoreçam acordos entre eles. 
A troca de informações dá-se num ambiente colaborativo, exigindo capacidade perceptiva e habilidade corporal, para extrair das diversas dinâmicas, aquelas que contribuem para comunicar os significados pretendidos.

Diante da variedade de opções disponibilizadas para serem descortinadas, o corpo tende inicialmente a vaguear entre distintas provocações até encontrar algo consistente para ser aprofundado. Tal procedimento, observado sob a perspectiva do pensamento complexo, que compreende a condição humana sob diferentes perspectivas, reside em experimentar seus objetos artísticos e com eles construir estruturas poéticas que exploram as singularidades sem perder-se as particularidades dos elementos envolvidos no processo. É um jeito de organizar o corpo e a dança criando espaços de interrelações entre os sujeitos, fortalecendo o exercício da escuta, que é um modo como cada um dos envolvidos pode contribuir a favor de uma ideia a partir de seus pontos de vistas e experiências para criar a dança em situações de imprevisibilidades.

Podemos considerar uma prática de como se "tecem uma relação de partilha de ideias e valores, preservando o caráter singular de cada projeto e seus principais organizadores" (LOUPPE, 2012, p.09), entendendo que todos os envolvidos estão engajados em uma "escuta" que se interrelaciona com as responsabilidades divididas em parceria. A escuta: "ouvir bem exige outro conjunto de habilidades, a capacidade de atentar de perto para o que os outros dizem e interpretar antes de responder, conferindo sentidos aos gestos e silêncios, tanto quanto às declarações" (SENNETT, 2012, p.26).

Como estamos falando de corpo que dança e da dança e, mais uma vez, do corpo com deficiência que dança, abordamos comportamentos e contextos que se diferenciam do mundo comum. São ações que se materializam resultantes de encontros que são tecidos por vias poéticas e que se ancoram no mundo concreto e nas características móveis. Tal empreendimento exige, sobremaneira, outro modo de percepção do objeto artístico. Tanto o corpo que dança (com ou sem deficiência), como o corpo do observador, ambos são mobilizados por provocações que se intensificam na relação corpo ambiente, e como tal, os acordos possíveis frente à 
diversidade não combinam com as ideias de um sujeito isolado e um objeto concluído.

O dançarino com deficiência ao se apropriar do seu corpo como fonte de informações, se torna menos vulnerável e mais engajado politicamente. Uma predisposição a romper com o exercício perverso dos discursos hegemônicos que os cercam. (CASTRO, 2007, p.60)

$\mathrm{Na}$ relação corpo ambiente, observamos que o modo como cada corpo se torna corpo interfere diretamente nas escolhas e tomadas de decisão. Aqui o corpo é agente de uma relação de coexistência, e, como tal, sofrendo e produzindo interferências, modificando-se ao mesmo tempo em que modifica e interfere no ambiente. O corpo, o corpo com deficiência necessariamente precisa traduzir por outras vias as informações que se dispõem, entretecendo as diferenças e rejeitando a concepção linear das tradicionais histórias de um mundo dado a priori (KATZ, 2005; LOUPPE, 2012).

No corpo, desafios se impõem com alcances imprevisíveis, pois é da natureza do corpomídia transformar-se ao contato com a diferença.

Sennett (2012) reforça que, na medida em que os laços se estreitam e as pessoas são estimuladas a prestar mais atenção umas às outras, a tendência é a comunicação tornar-se mais complexa. Isso porque é da natureza do corpo transformar-se através de surpreendentes descobertas do encontro com a diferença. Encontros fortuitos de qualidades e potencialidades dos sujeitos envolvidos são, nesse jogo de acordos, levados em consideração, fortalecendo o posicionamento político. Aqui, o pensamento decolonial encontra o lugar para agir quando os sujeitos envolvidos clamam seus lugares de direito na ordem social, política, cultural e econômica. Se revelados ou obscurecidos, ao prestarmos mais atenção aos outros e às ocorrências do entorno, os lugares, sejam eles concretos ou de experiências sensíveis a serem comunicados via corpo, organizam-se na relação de troca de informações com o ambiente e não abrem mão do contexto.

Compreender o corpo, a dança e a dança do corpo com deficiência não como ações isoladas, mas que se dão em relações de coexistência, da cooperação que se 
dá face a face para gerar solidariedade e das ansiedades provocadas pelas diferenças, sejam de natureza política, religiosa, étnico-racial, erótica, social, cultural, arquitetônica, pois fazem parte desse intricado contexto onde o corpo encontra suas resistências. Os autores Hernandez (2010) e Sennett (2012), consideram que os conhecimentos concebidos em conjunto e colaborativamente construídos, observam os efeitos dos acordos elaborados, sobretudo, e põem no âmbito das discussões o lugar de responsabilidades mútuas. Assim, todos são responsáveis por suas ações no mundo.

Em nossas discussões, levamos em consideração as relações entre o corpo, o ambiente e a comunicação, suas ações/pensamentos políticos de engajamento, para afirmar a ideia de que o corpo em sua multiplicidade e em seus processos dar-se-á na relação de coexistência. Entender que o corpo da pessoa com deficiência e seus processos dar-se-ão em uma relação de coexistência, sob diferentes perspectivas, distancia-nos das ideias simplistas para dar voz à multiplicidade de agentes que reforçam a ideia de que as informações tendem a operar dentro de um processo permanente de comunicação. Qualquer ação, seja de que ordem for, desencadeará uma série de acontecimentos que irão se organizar e expor signos viabilizadores de espaços relacionais, e, sobretudo, o acolhimento e atravessamento por diversas áreas do conhecimento.

O corpo que dança a partir de provocações mediadas pela improvisação (seja com deficiência ou não) depara-se com situações que não tem um rumo certo, direto ou um objetivo concreto, mas, e sobretudo, proposições em rotas que se bifurcam e se impõem desafios em continuidades de um fim provável a ser modificado mais adiante... mais adiante e mais adiante... e lá adiante, quem sabe?

Entender que o fato da pessoa com deficiência que dança não ter determinadas capacidades motoras que o corpo dito ideal para a dança, não impede que esse dançarino possa utilizar do seu corpo com expressividade, explorando-o poeticamente e comunicando-se de acordo com suas capacidades corporais exatamente o mesmo que se pede do corpo não deficiente, em um espetáculo de 
dança. O que os diferenciará é o mesmo que diferencia os corpos: as capacidades corporais de cada qual.

Essa proposição pode ser confirmada nos estudos desenvolvidos pelo cientista cognitivo Antonio Damásio em Os Mistérios da Consciência (1999), quando este explica que as imagens que se constroem na mente são resultados de interações entre cada corpo e os objetos que o rodeiem. Interações que são mapeadas em padrões neurais de acordo com as capacidades do organismo. Significa dizer que qualquer ação do corpo no mundo - a mais simples que for - será informação. Informações que alimentam um processo de encadeamento de aprendizagem organizado pelo cérebro, em que cada nova aprendizagem servirá de pré-requisito para outras, similares e mais complexas. Trata-se de um processo que opera em rede e apoia-se tanto no corpo como em suas características evolutivas.

Quanto à cultura e ao conhecimento, o cérebro dispõe de uma memória hereditária, bem como de princípios inatos de organização de conhecimento, que estão diretamente relacionados ao corpo histórico de cada pessoa... O corpo com deficiência aí está presente. As experiências corporificadas revelam-se de formas diferenciadas em todas as ações realizadas pelo corpo. Uma vez que cada informação exista para o corpo na medida em que seja corporalmente vivenciada, cada corpo a vivenciará de acordo com as suas possibilidades e características pessoais e sempre em troca com o ambiente. As relações de troca vão construindo os ajustes adaptativos entre corpo e ambiente, favorecendo sua permanência no mundo, impulsionando-o em direção à conquista da autonomia (VIEIRA, 2006). Interferências que estão enredadas firmemente em um processo ininterrupto de reconhecimento. O resultado exposto sempre revelará e situará o nível de conhecimento do dançarino, pois seu corpo é sempre corpomídia de si mesmo, seja com deficiência ou sem deficiência. $E$, esse corpomídia com deficiência que pode comunicar modos de ser visíveis e invisíveis estará sempre contaminando e sendo contaminado, bastando um olhar, um sutil olhar, um aceno, qualquer imagem. Todas as informações que entram em contato com um corpo agem nele de alguma forma $\mathrm{e}$ ele age no mundo, mudando-se mutuamente. Logo: 
Apresentar o corpo como uma experiência desta ordem significa assumir um trânsito permanente entre biologia e cultura, uma vez que a habilidade de dançar se constrói através do sensório motor do corpo, que, como qualquer outro organismo se transforma pela informação que agrega (GREINER; KATZ, 2005, p.85).

O discurso do corpo com deficiência que dança constrói uma imagem confiável de sua própria pessoa em função das crenças e valores recebidos e compartilhados embora, excluídos estejam. Diferenças e deficiências defrontam-se com barreiras distintas que devem ser superadas de maneiras singulares e de acordo com a peculiaridade de cada situação. O modo de ser do corpo com deficiência não elimina em hipótese alguma suas diferenças e potencialidades, por isso mesmo aqui se está exigindo, insistindo, repetindo, resistindo, evocando, expondo pensamentos que desafiam os padrões predeterminados e excludentes.

Com um olhar mais cuidadoso, ver-se-á que existe um fluxo, um continuo de ações que orientam que o "outro" será sempre outro, usando as palavras de Bauman (1999), aquele sujeito estranho e diferente que solapa a organização espacial. É importante que seja assim, o outro contextualizado no cenário social e político representa o meio de resistência, um modo de impulsionar para adiante, obrigando e forçando sempre novos acontecimentos - o que constitui uma ameaça constante às fronteiras dos grupos que tentam delimitar suas identidades. Mas, que identidade se pode buscar uma vez que se está em fluxo? (CASTRO, 2007, p. 94)

Vocês, bípedes, me cansam!

Vocês, bípedes, me...!

Vocês, bípedes...!

Vocês! 


\section{REFERÊNCIAS}

AGAMBEN, Giorgio. Homo Sacer, o poder soberano e a vida nua. Belo Horizonte: UFMG, 1999.

BAUMAN, Zygmunt. Modernidade Líquida. Rio de Janeiro: Jorge Zahar, 1999.

CARMO, Carlos E. O. Desnudando um corpo perturbador: a "bipedia compulsória" e o fetiche pela deficiência na Dança. Revista Tabuleiro de Letras (PPGEL/UNEB), Salvador, v. 13, n. 2, p. 75-89, 2019.

CASTRO, Fátima C.D. Corpo sitiado..., a comunicação invisível. Dança, Rodas e Poéticas. Tese (Doutorado em Comunicação e Semiótica) - Pontifícia Universidade de São Paulo, São Paulo, 2007.

CHURCHLAND, Paul M. Matéria e Consciência. São Paulo: Unesp. 2004.

DAMÁSIO, Antonio. O Mistério da consciência. São Paulo: Companhia das Letras, 1999.

DEWEY, John. Arte como Experiência. São Paulo: Martins Fontes, 2012.

GREINER, Christine; KATZ, Helena. Arte e cognição. Corpomídia, Comunicação, Política. São Paulo: Annablume, 20015.

HERNANDEZ, Fernando. Educación y cultura Visual. Barcelona: Octaedro, 2010.

KATZ, Helena. UM, DOIS, TRÊS. A dança é o pensamento do corpo. Belo Horizonte: FID, 2005.

LLINÁS, Rodolfo. El cérebro y el mito del yo. Bogotá: Germiis, 2003.

LOBO, Lilia Ferreira. Os infames da história: pobres, escravos e deficientes no Brasil Rio de Janeiro: Lamparina, 2008.

LOUPPE, Laurence. Poética da dança contemporânea. Lisboa: Orfeu Negro, 2012.

MCRUER, Robert. Crip theory: cultural signs of queerness and disability. New York: New York University Press, 2006.

MIGNOLO, Walter D. Desobediência epistêmica: a opção descolonizal e o significado de identidade em política. Cadernos de Letras da UFF: Dossiê: Literatura, língua e identidade, Niterói, n. 34, p. 287-324, 2008.

NOË, Alva. Action in perception. Massachusetts: Massachusetts Institute of Technology, 2004.

SENNETT, Richard. Juntos. Os rituais, os prazeres e a política da cooperação. Rio de Janeiro: Record, 2012. 
SILVA, Tomaz Tadeu. Identidade e diferença: a perspectiva dos estudos culturais (org.). Stuart Hall, Katrhyn Woodward, 15 ed. Petrópolis, RJ: Vozes, 2014.

VIEIRA, Jorge Albuquerque. Ciência-formas de conhecimento: arte e ciência - uma visão a partir da complexidade. Fortaleza: Expressão, 2006

ZOBOLI, F.; BARRETO, S. J. A Corporeidade como fator de inclusão de alunos com necessidades especiais nas aulas de educação física. In: RODRIGUES, D. Atividade motora adaptada: a alegria do corpo. São Paulo: Artes Médicas, 2006. 